\title{
EDITORIAL
}

\section{Ethical, legal and social issues: out in the open}

\author{
Rebecca F Furlong*
}

The field of genomic medicine moves quickly, and previously unrealized ethical issues are becoming apparent as new technologies are invented, novel data emerge and clinical applications are established. In the three years since the launch of Genome Medicine, we have seen discussion panels at genomics conferences tackling such topics as return of research results to participants and physician education in the genomic era, while headlines have been made by the Genetic Information Nondiscrimination Act [1], the Myriad Genetics patent litigation [2], and the US Food and Drug Administration's take on direct-to-consumer testing [3].

Considerations of the ethical implications of genomic technologies and data are crucial to the implementation of genomic advances for improving human health. Work in the ethical, legal and social issues (ELSI) field does not always fit the standard Research article format, but broad, transparent access to these analyses and discussions is essential if they are to be integrated into the field of genomic medicine. In this issue of the journal, we introduce a peer-reviewed open-access article type, Open Debate, to accommodate novel and scholarly arguments that are informed by analysis and discussion, not just practical research. In the first article of this new type, Timothy Caulfield, Shawn Harmon and Yann Joly investigate the conflicts between open science and commercialization in genomics research [4].

Genomics has a culture of open data dating to before the time of the Human Genome Project, with the principles of accessibility formalized in the Bermuda agreement leading to an ongoing general principle that sequencing data should be released into the public domain as soon as possible after they are generated, and at least prior to publication. In the burgeoning field of medical sequencing, this principle has been tempered somewhat by considerations of patient privacy (a topic for another day), but as a rule, openness in genomics research continues to be both integral and essential. For example, it is hard to imagine how the recent explosion of genome-wide association studies, with their huge

*Correspondence: rebecca.furlong@genomemedicine.com

Genome Medicine, BioMed Central, 236 Gray's Inn Road, London WC1X 8HB, UK sample sizes, could have taken place without collaboration and data sharing. However, researchers are also increasingly encouraged to commercialize their research to speed product development and for monetary gain, which implies secrecy and competition. In their article, Caulfield and colleagues carry out an exploratory analysis of these two aspects of the policy guidelines from major funding bodies in the UK, US and Canada, concluding that these two opposing forces in genomics research may not be irreconcilable, but that a flexible middle way must be sought.

In the spirit of openness and fostering debate, we encourage our readers to use the Comments facility available on our website, or tweet @genomemedicine, to join in the discussion. The transition to genomic medicine is dependent upon the participation of researchers, ethicists, lawyers, clinicians and patients, and we'd like to hear your views.

\section{Competing interests}

The author declares that she has no competing interests.

\section{Acknowledgements}

Many thanks to the rest of the Genome Medicine editorial team for stimulating discussions and valuable comments on this article.

\section{References}

1. Law Seeks to Ban Misuse of Genetic Testing

[http://www.nytimes.com/2009/11/16/business/16genes. html?adxnnl=1\&adxnn|x=1330356285-TFr74g22SiiVmFmZdkYVHw].

2. Breast cancer gene patents judged invalid [http://www.nature.com/news/2010/100330/full/news.2010.160.html].

3. FDA panel advises caution on personal genetic testing

[http://articles.latimes.com/2011/mar/09/nation/ la-na-genetic-testing-20110309].

4. Caulfield T, Harmon SHE and Joly Y: Open Science Versus Commercialization: A Modern Research Conflict? Genome Medicine 4:17.

Published: 27 February 2012

\section{doi:10.1186/gm317}

Cite this article as: Furlong RF: Ethical, legal and social issues: out in the open. Genome Medicine 2012, 4:18. 